\title{
Application of Fuzzy AHP Approach to Selection of Organizational Structure with Consideration to Contextual Dimensions
}

\author{
Alireza Aslani ${ }^{1}$, Feryal Aslani ${ }^{2}$

\begin{abstract}
${ }^{1}$ University of Vaasa, Faculty of Technology, Industrial Management Department, 65101, Vaasa, Finland and Carnegie Mellon University, Department of Engineering and Public Policy, 5000 Forbes Ave, Pittsburg, PA 15213, USA (visiting scholar), alireza.aslani@uwasa.fi (corresponding author)

${ }^{2}$ University of Tehran, Faculty of Management, Information Technology Management Department, Tehran, Iran,
\end{abstract} \\ feryal.aslani@gmail.com
}

\begin{abstract}
The literature of organizational structure design is relatively rich along with conceptual and complex patterns. This complexity arising from the number of elements and numerous relations in addition to the nature of variables. Thereby, the lack of operational decision-making models is felt to propose adequate structural designs in practice. In this article, the researchers employ a fuzzy multi attribute decision making model (FMADM) to select the most suitable organizational structure based on expert's judgments and by deploying contextual dimensions of the organization. Since the organizational changes especially in the structural levels are along with resistances among involved staffs, the implementation of this model is a supportive tool in addition to help the managers to make a qualified decision and change.
\end{abstract}

Keywords: Organizational Structure Designing, Business Process Reengineering, Development Management, Integration, Fuzzy AHP

\section{Introduction}

Change occurrence in a phenomenon is an admitted principle, in particular, a planned and opportune change is essential for an organization. Change and development with utilization of recognized approaches such as business process re-engineering, total quality management, and organizational downsizing are based on a primary assumption; organizations should observe their business with a process-oriented perception to concentrate again on their main responsibility and fulfillment of costumers' needs (Grover et al., 1995). Business process is composed those basic activities that are not restricted to duty boundaries in an organization. Meanwhile, one of the managerial significant decisions in organizations occurs in a frame of new organizational structure in order to integrate process of organizational departments and units. To make a right decision, managers and decision makers need to be informed about the process aspects of the contextual and structural dimensions of the organization (Sethi and Nicholson, 2001).

Although the literature of organizational structure design is relatively rich, it lacks operational and decision making models to propose adequate structural designs (Bafandeh,
2009; Chou and Cheng, 2006; Adler, 2011). Since organizational design theories are mainly conceptual patterns, the complexity of subjects provide problems in order to actual implementation in the organizations. This complexity is because of the number of elements and subsequently their relations in addition to the nature of used variables. For instance, most of the variables used for definition and explanation of the organizational subjects are linguistic variables. The linguistic variables are not precise and explicit in contrast to quantitative ones (Cernancky et al., 2007).

This research in the frame of a fuzzy multi-attribute decision-making model (FMADM), and by deploying contextual dimensions of the organizations discusses about the selection of the suitable organizational structure in the commercial departments of a sample organization. The fuzzy approach is employed in this research in light of the complicated, vague, and uncertain nature of the organizational structure, and contextual dimensions. To make a final decision, the judgments of the staffs and professionals in the different levels of the organization are used. Since the organizational changes especially in the structural levels are along with some resistances among involved different staffs, the implementation of group

Received: $17^{\text {th }}$ February 2012; revised $4^{\text {th }}$ July 2012; accepted $3^{\text {rd }}$ September 2012 
decision-making models and participating beneficiary staffs would be a supportive tool in this kind of strategic decisionmaking.

\section{Literature Review}

Today organizations change with the development of internal and external environments. Even efficient organizations need to improve and develop their structures. The structure design is the process of selecting an organizational structure that can be applicable for a certain strategy and environment (Daft, 2009).

Structural development in organizations has been under effect of duty-oriented vision for a long time. According to this vision, organizations are considered as a hierarchy of authority and control in which activities are aggregated and sorted in duty-organizational sections (Robbins, 2006). Therefore, groups of experts are established in the organization that emphasize on their limited functional tasks.

In recent years, various concepts and tools have been introduced for organizational developments that are mostly focus on business processes as a concept to design an organization. Re-engineering of business processes is a frequent example in which the organizational losses are recognized and resolved by emphasizing on the main organizational processes, i.e. those create added value for internal and external costumers (Damjanovic, 2010).

There is an incompatibility between expectations and goals of re-engineering, and what is happening in reality (Al-Mashari and Zairi, 1999). Studies indicate that the outputs of re-engineering programs still consider to the organizations as a structure instead of a set of processes affected by the organizational variables. Thereby, in most cases, re-engineering is considered wrongly as a tool for minimizing the organization size. Therefore, it seems before any development in the organizational structure, the important and effective variables on organizational structure design must be recognized. These variables named contextual dimensions of the organization: Strategy, Environmental uncertainty, Technology, Size of the organization, and Culture (Daft, 2009). They are dynamic and complex in order to application in organizational structure design.

\subsection{Contextual Dimensions of the Organization}

Contextual dimensions address the entire of organization and its conditions, as well as determination of structural dimensions of the organization. They are composed of strategy, environmental uncertainty, technology, size of organization and organizational culture (Daft, 2009). The elements of structure should be selected regarding to their internal compatibility and the situation of the organization, i.e. size and background, environment of activity and etc. (Mintzberg, 2007). In this article, these dimensions are employed as principal criteria required for designing and selection of organizational structure. The structure that has the most conformity with the contextual dimensions of the organization is in priority for selection and implementation. Table 1 marks some point of each dimensions briefly.

\subsection{Incorporation and Integration of Organizational Processes}

Studies show that incorporation and integration of work processes are two of the keys success factors to achieve synergy in organization (Ketchen and Hult, 2007). Meanwhile, incorporation and integration are two of the manager's interests as they believe that incorporation and integration can speed growth, efficiency and performance improvement, and cost reduction. Re-engineering of processes is one of the most common process approaches that ascertain the integration idea and unification of managers. According to the assumptions of re-engineering, the internal operations are designed and structured in the format of processes. The processes are a set of internal operations that totally fulfill a unique goal and create a unique added value for the organization (Hall and Johnson, 2009).

One of the most crucial processes in manufacturing and service organizations is commercial sector. This area in a manufacturing organization consists of the processes such as purchasing, sale, marketing, ordering, warehousing, financial affairs and etc. In most of the organizations considering to their size, these processes are recognized in the form of independent offices or related departments. Due to mutual dependence and dynamic nature of the commercial departments, exposure of interactions and conflicts are permanently expected. For instance, conflicts exist between sales and marketing units about pricing and advertising, sales and finance units about the commitments of buyers, purchasing and programming of orders and etc. (Bennett and Savani, 2004). In this article, the authors have focused on the selection of the suitable organizational structure.

\section{Case Study Overview}

The commercial departments of an after sale services organization in automobile industry in Iran was selected as a case study of the research (CS). In after sales services organizations, commercial sectors are like units engaging in the line of fire. Since the main factor for costumer's satisfaction in an automobile manufacturer is the quality of after sale services (i.e., supplying spare parts), the strategic role of the commercial departments insight of some costumer's satisfaction indicators such as service level and etc. are important. Second, these organizations have service natures that are generally costly for manufacturers. Therefore, commercial activities of the after sales services organizations are very important for shareholders and automobile manufacturer from profitability aspect. Commercial activities in these organizations consist of supplying and distribution of spare parts to their dealers and customers.

CS is the biggest private organization in the field of after sale services in Iran and owns 180 authorized dealers in automobile sale and after sale services network operating with more than 300 direct employed staff and 1500 employees working in distribution sectors. The organization covers required services and spare parts for more than 10 different automobiles in cooperation with domestic and international 
Table 1. Description of contextual dimensions

\begin{tabular}{|c|c|c|}
\hline No. & Dimensions & Brief Description \\
\hline 1 & 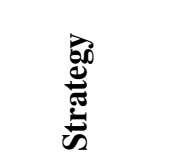 & $\begin{array}{l}\text { * Since managers design organizational structure to achieve the goals, the structure should principally } \\
\text { follow the strategy, and change when it varies (Daft, 2009). } \\
\text { * The relation between strategy and structure were first studied by Alfred Chandler (Hatch and Cunliffe, } \\
\text { 2006). }\end{array}$ \\
\hline 2 & 氞 & $\begin{array}{l}\text { * Since organizations encounter environments with different levels of uncertainty, the management in an } \\
\text { organization endeavors to reduce the environmental uncertainty by changing the structure. } \\
\text { * The environmental uncertainty is particularly caused by unpredictability of different groups such as } \\
\text { suppliers, competitors and costumers. Those organizations that are running in unconfident environments } \\
\text { must have a flexible structure to respond the uncertainty, compare to those work in confident environments } \\
\text { (Hatch and Cunliffe, 2006). } \\
\text { * The organizational structure of the companies with highly confident environments is focused with for- } \\
\text { mal rules and regulations. In contrast, an uncertain environment demands further organizational flexibility } \\
\text { and internal independence. }\end{array}$ \\
\hline 3 & 㟒 & $\begin{array}{l}\text { * The first study about technology and its relation with the structure, which is still reliable, is attributed to } \\
\text { Ms. Woodward. She classified companies in regard with one of the three types of technology, unit produc- } \\
\text { tion, mass production and process production (Robbins, 2006). } \\
\text { * Perrow focused on knowledge-based technology instead of concentration on production technology } \\
\text { (Robbins, 2006). In his model, Perrow offers four service technology types based on two respective } \\
\text { dimensions of task variability and problem decomposability. These technologies consist of repetitive } \\
\text { (invariable), engineering, artistic and industrial, and non-repetitive ones. }\end{array}$ \\
\hline 4 & 赵 & $\begin{array}{l}\text { * The number of employees is an adequate index to realize the size of organization (Robbins, 2006). } \\
\text { * Size of organization effects on the structural dimensions of that organization by an inclining rate. On the } \\
\text { other words, the structural dimensions of small organizations are highly sensitive, compare to the larger } \\
\text { ones, to the growth in staff members (Daft, 2009). }\end{array}$ \\
\hline 5 & 冚 & $\begin{array}{l}\text { * Organizational culture is one of the key factors to achieve organizational strategies and goals, and } \\
\text { change management in addition to improving the organizational efficiency. } \\
* \text { Organizational culture and organizational structure are in mutual association so that the organizational } \\
\text { structure is affected by organizational culture, but is effective in strength and consolidation of its respec- } \\
\text { tive organizational culture (Daft, 2009). } \\
* \text { Those structures that benefit from higher flexibility and power of compatibility are powerfully able to } \\
\text { consolidate and stabilize their organizational culture. In an organization with a characteristics of high level } \\
\text { culture such as; authority bestowing, the spirit of innovation and creativity, risk-taking, harmony and toler- } \\
\text { ance of ambiguity, it is not possible to design a structure that merely insists on running the organizational } \\
\text { relations through the limited channel of hierarchy, or power accumulation instead of distribution, and } \\
\text { restrictive bureaucratic regulations (Hatch and Cunliffe, 2006). }\end{array}$ \\
\hline
\end{tabular}

spare parts supply companies from various countries including Japan, China, India, Germany and etc. The company could reach the net sale of 27.60 million $\$$ with $45 \%$ of the market share in 2010.

With respect to development of the market which is resulted by automobiles manufacturing and automobiles import done by the mother company, the financial indicators in commercial sector depicts a decrease in the market share of spare parts in CS. Therefore, while the average ratio of market volume growth to the sale growth has been 1.53 in three recent years, the average percentages of budget and profit attainment were $85 \%$ and $73 \%$ in 2010 . In light of this strategic gap, the CS commenced the re-engineering project of their processes with especial focus on the commercial departments. The result of re-engineering realized a gap in the commercial structure of the organization that was a subset of task structure. Figure 1 shows the organizational chart of the CS(commercial sections) at the beginning of re-engineering project.

After comparing the common and prevalent organizational structures in similar companies such as TOYOTA, FORD, VOLVO, MAZDA, and the gap analysis, four new organizational structures (scenarios) were introduced in the re-engineering project in order to implement in CS.

\subsection{Task type: Reform Current Structure and Tasks Integration (S1)}

In the structure based on task, the activities are sorted in light of the nature of job functions. For example, sale staffs are 


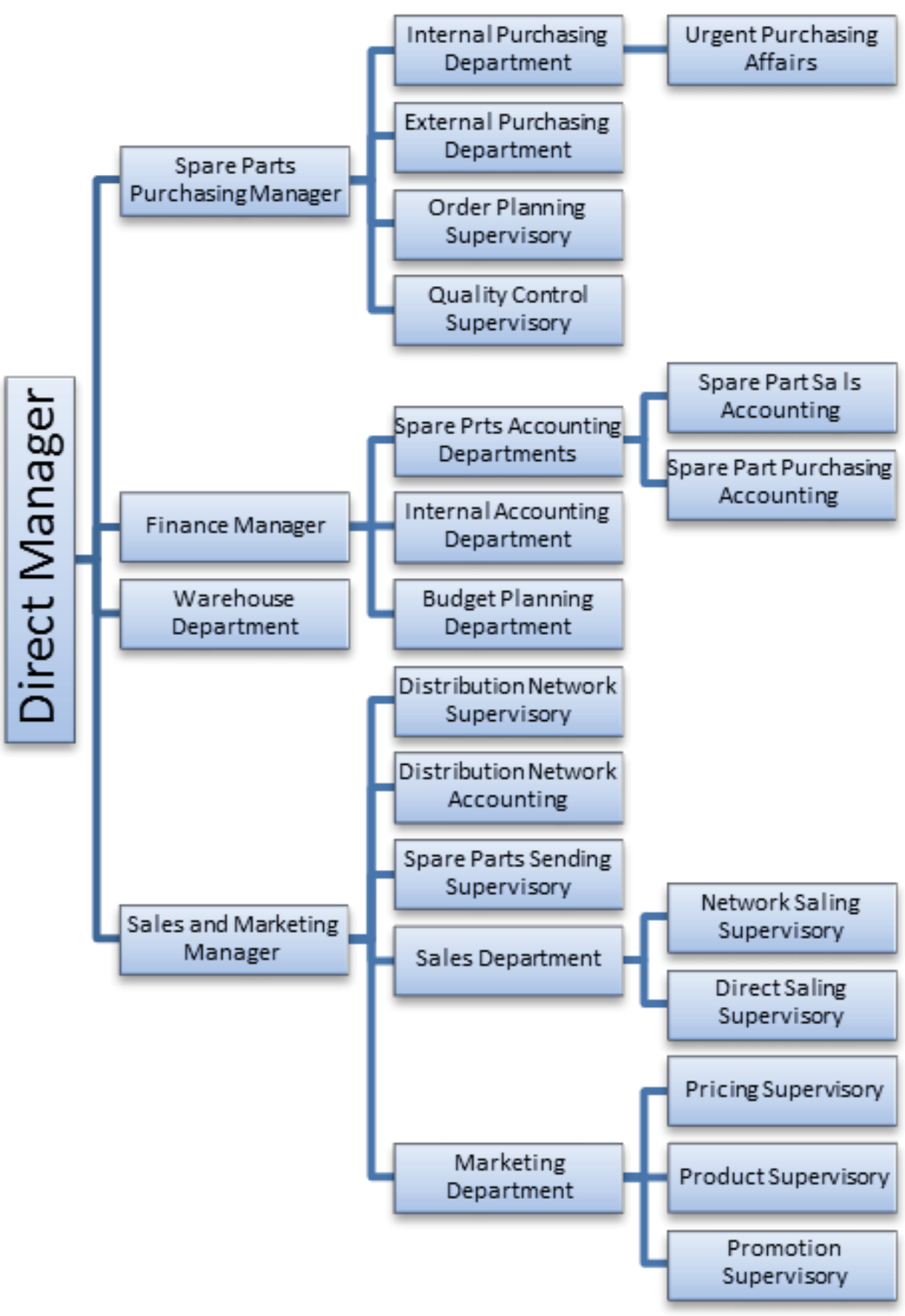

Figure 1: CS's organizational chart- commercial section-(Source; Human Resource Department)

settled in the sale unit and head of the unit is responsible for all the activities (Dessler, 2007). The previous structure of CS was designed based on this frame. After re-engineering of commercial processes, changes are suggested as following:

1. Integration of "spare part purchasing management" with "sales and marketing management" in a new frame named "spare parts supply chain deputy" and eliminating former managements,
2. Integration of "spare parts sending supervisory" at "sales and marketing management" with "spare parts quality control supervisory" at "purchasing department",

3. Integration of "orders planning supervisory" with "product supervisory" of the "marketing department",

4. Submission and integration of "distribution network supervisory" at "sale and marketing management" with "after sale services management", beyond the commercial departments, 
5. Establishment of "finance affairs supervisory" under direct supervision of "supply chain deputy" and "integration of "dealers accounting supervisory" in it,

A new structure decreases about $14 \%$ of the staffs. In addition, one manager and three supervisor positions will be removed.

\subsection{Product Type: Reform Organizational Structure Regarding Product Diversity (S2)}

In the structures based on the product, different parts of commercial sector in the organization are organized in respect of the product type, service type, and a set of products, work type, basic plans or programs or benefit points (DuBrin, 2006).

In this scenario, two substantial changes are offered for CS. First, the entire tasks affairs of each automobile ( i.e., automobile A) including marketing, sale, and ordering integrate in new units with supervisors under direct supervision of marketing manager. For instance, a new department related to automobile $\mathrm{A}$ is introduced, and the whole tasks of spare parts ordering, marketing, and sale to distribution network is transferred to the new department (three new departments for CS). The second change is to integrate the "distribution network supervisory" and "promotion supervisory" in a unit under title of "distribution network development supervisory."

The number of staff in new structure decreases about $9 \%$.

\subsection{Based on Region: Reform Organizational Structure Based on Geographical Distribution (S3)}

One of the categories of organizational structure is based on the customer dissipation. The most prevalent structure of this classification is based on geographical region (DuBrin, 2006). In this structure, the organizations can be compatible with the requirements of each region. However, the salient point that may be challenging is coordination between the regional units.

Based on this frame, the entire affairs associated with marketing, sale, ordering, and finance of 180 distribution networks are integrated in the form of three regional departments: "north and west", "central", and "east and south" for CS.

In this scenario, the number of staff in commercial departments will increase about $2 \%$.

\subsection{Matrix Structure (S4)}

Having two structures of task and product oriented simultaneously is one of the exclusive characteristics of Matrix structure (Dessler, 2007). This structure is suitable for the environments with uncertainty and complicated technology (Daft, 2009).

Three significant changes should be happened for CS to frame this structure:

1. Integration of "sales and marketing" and "purchasing managements" in the form of a new department named "commercial management,"
2. The units of marketing, ordering, and spare parts purchasing (internal and external) are integrated in the form of four supervisors,

3. Sale department operates independently,

This scenario increases the number of staff about $9 \%$.

\section{Research Methodology}

The research method of this work is an applied research insight of purpose, and a descriptive-analytical and mathematical research from data gathering viewpoint (Sarmad, 2009). The innovation aspects of this research are as following:

- Comprehensive Assessment: The utilized approach suggests the evaluation and selection of the best suitable organizational structure with respect to judgment of engaged staffs of the organization, and contextual dimensions.

- Fuzziness: The world is changing constantly and this trend may not provide the certainty of past events. In this regard, the inclination for implementation of fuzzy logic in the literature of management and operations research has been increased. The fuzzy logic is used in this article due to the high-efficiency of it.

- Flexibility: The used analytical approach has a high flexibility for evaluation of organizational structures. For instance, the managers as main decision makers can change the weights of criteria without any injury to the logic of approach.

\subsection{The implementation of Fuzzy AHP for Selection of Suitable Organizational Structure}

Since the decision criteria in this research are qualitative, prioritization of suitable organizational structure is considered as a complex model of multi-criteria decision-making (MCDM) (Patton, 2002). This means ordinary MCDM models are inefficient to adjust with the real conditions caused by conversion of qualitative variables into quantitative ones. Therefore, a suitable multi-attribute fuzzy model of decision-making was employed for data analysis. In this approach, to reduce the undesirable impacts in conversion of qualitative variables, linguistic variables and triangular fuzzy numbers were utilized (Momeni, 2007). To formulate the model and due to the complexity of criteria, the Fuzzy AHP and Extent Analysis Method were used. The Analytic Hierarchy Process (AHP) is one of the best and valid methods in multi-criteria decision-making (MCDM) (Ishizaka and Labib, 2011). The group pairwise comparisons also were implemented to weight the criteria that have advantages like more consistent ability for respondents and both qualitative and quantitative information can be compared by using informed judgments to derive weights and priorities (Hwang and Yoon, 1981; Aslani et al., 2012a; Aslani et al., 2012 b). 


\subsubsection{Fuzzy AHP and Extent Analysis Method (EA)}

The extend analysis method (EA) was presented in 1996 by Chang(Chang, 1996). Triangular Fuzzy Numbers (TFN) is used in this model. A TFN is characterized by the three folds (l, m, u) (Figure 2). Fuzzy algebraic operations can be calculated for triangular fuzzy numbers by using extension principle as following (Azar, 2008):

$(\mathrm{L} 1, \mathrm{M} 1, \mathrm{U} 1)+(\mathrm{L} 2, \mathrm{M} 2, \mathrm{U} 2)=(\mathrm{L} 1+\mathrm{L} 2, \mathrm{M} 1+\mathrm{M} 2, \mathrm{U} 1+\mathrm{U} 2)$

$(\mathrm{L} 1, \mathrm{M} 1, \mathrm{U} 1)-(\mathrm{L} 2, \mathrm{M} 2, \mathrm{U} 2)=(\mathrm{L} 1-\mathrm{L} 2, \mathrm{M} 1-\mathrm{M} 2, \mathrm{U} 1-\mathrm{U} 2)$

$(\mathrm{L} 1, \mathrm{M} 1, \mathrm{U} 1)^{*}(\mathrm{~L} 2, \mathrm{M} 2, \mathrm{U} 2)=(\mathrm{L} 1 \mathrm{~L} 2, \mathrm{M} 1 \mathrm{M} 2, \mathrm{U} 1 \mathrm{U} 2)$

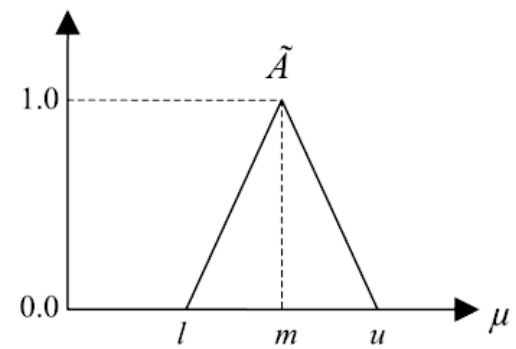

Figure 2: Triangular Fuzzy Number

For each row of pairwise comparisons matrix, the value that is a TFN is defined as follow (Chang, 1996);

$$
S k=\sum_{j=1}^{n} M k j \times\left[\sum_{i=1}^{m} \sum_{j=1}^{n} M i j\right]^{-1}
$$

$\mathrm{K}$ is line number, and $\mathrm{i}$ and $\mathrm{j}$ show alternatives (suggested organization structures) and criteria (contextual dimensions).

The degree of possibility of $\mathrm{M} 1>=\mathrm{M} 2$ is defined as (Chang, 1996):

$$
\begin{array}{ll}
\mathrm{V}(\mathrm{M} 1>=\mathrm{M} 2)=1 & \mathrm{~m} 1>=\mathrm{m} 2 \\
\mathrm{~V}(\mathrm{M}>=\mathrm{M} 2)=\operatorname{hgt}(\mathrm{M} 1 \cap \mathrm{M} 2) & \text { Other }
\end{array}
$$

Based on a mathematic principle:

$$
h g t(M 1 \cap M 2)=\frac{u 1-L 2}{(u 1-L 2)+(m 2-m 1)}
$$

The degree possibility of a TFN to be greater than other can be defined by;

$$
\mathrm{V}(\mathrm{M} 1>=\mathrm{M} 2 \ldots \mathrm{Mk})=\mathrm{V}(\mathrm{M} 1>=\mathrm{M} 2) \text { and } \ldots \text { and } \mathrm{V}
$$
(M1>=Mk)

The weights of criteria in pairwise comparisons are calculated according to follow;

$$
\mathrm{W}^{\prime}(\mathrm{xi})=\min \{V(s i \geq s j)\} \quad \mathrm{k}=1,2, \mathrm{n}
$$

Then the weight vector of criteria is given by; $\mathrm{W}^{\prime}=\left[\mathrm{W}^{\prime}(\mathrm{x} 1), \mathrm{W}^{\prime}(\mathrm{x} 2), \ldots, \mathrm{W}^{\prime}(\mathrm{xn})\right]^{\mathrm{t}}$

Where $\mathrm{W}^{\prime}$ is a nonfuzzy number.

\subsection{Data collection and analysis}

Figure 3 shows the hierarchy decision-making model of the research. In the next step, a questionnaire consists of pairwise comparisons of five criteria and four alternatives with respect to the criteria were designed. In order to correct the transfer of contextual dimensions concepts to responders, three

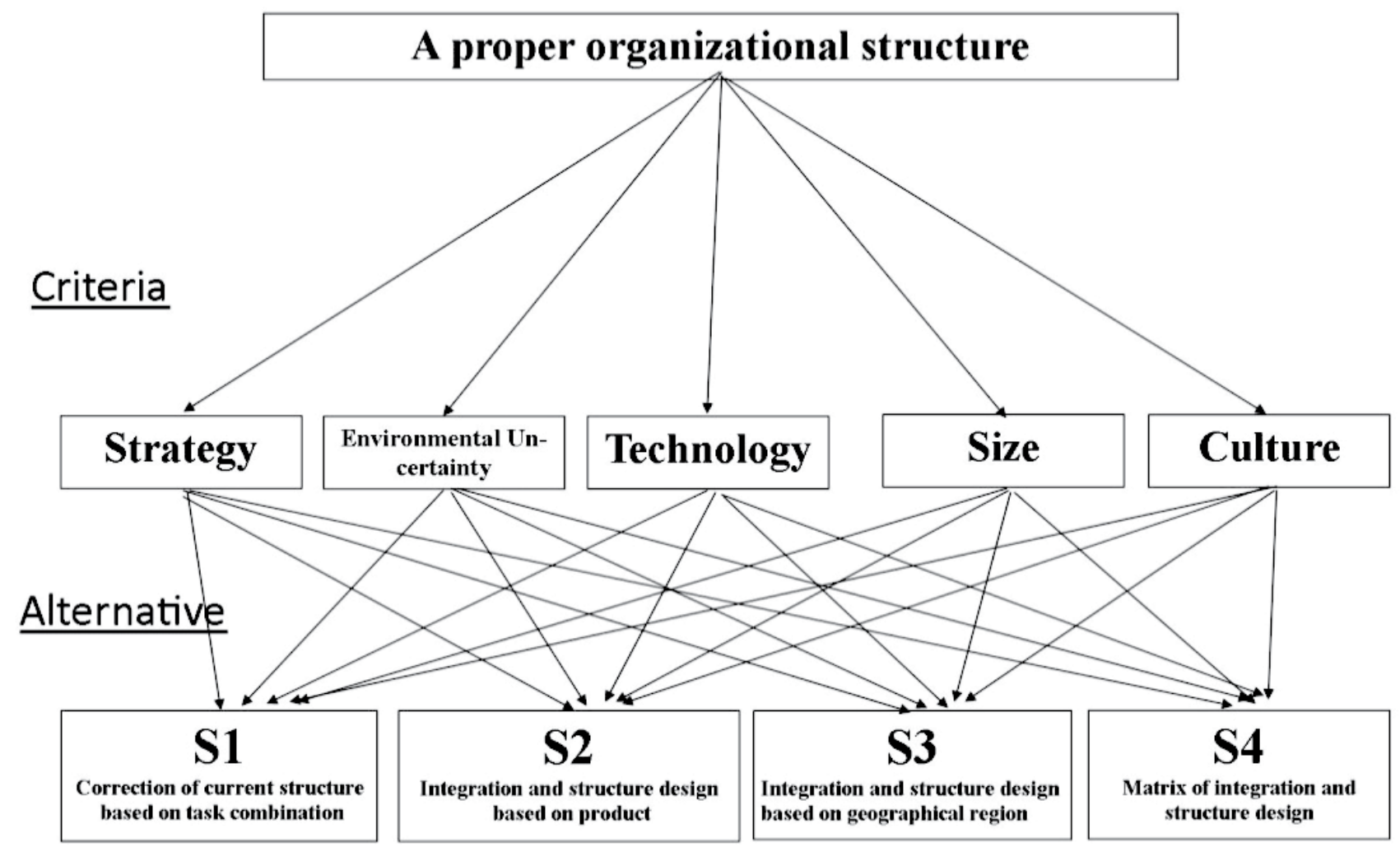

Figure 3: Decision making model 


\begin{tabular}{|l|l|l|}
\hline Intensity of importance & Definition & Explanation \\
\hline 1 & Equal importance & Two activities contribute equally to the objective \\
\hline 3 & Moderate importance & Experience and judgement slightly favour one over another \\
\hline 5 & Strong importance & Experience and judgement strongly favour one over another \\
\hline 7 & $\begin{array}{l}\text { Very strong } \\
\text { importance }\end{array}$ & $\begin{array}{l}\text { An activity is strongly favoured and its dominance is demonstrated in } \\
\text { practice }\end{array}$ \\
\hline 9 & Absolute importance & $\begin{array}{l}\text { The importance of one over another affirmed on the highest possible } \\
\text { order }\end{array}$ \\
\hline $2,4,6,8$ & Intermediate values & Used to represent compromise between the priorities listed above \\
\hline
\end{tabular}

Figure 4: Pairwise comparison scales (Saaty and Peniwati, 2007)

lines interpretations related to criteria and organization were expressed in pairwise comparison of each criteria. Also the phrasing of the questions was formulated carefully in order to reflect the scales intensity of relative importance (Figure 4) (9 to 1/9 Saaty Scales) (Saaty and Peniwati, 2007). The equal numbers in which used in the questionnaire were based on TFN.

The validity of the questionnaire was confirmed by using the standard table of AHP method (Saaty and Peniwati, 2007; Aslani et al., 2012a). The questionnaires were distributed among 43 staffs in all levels of relevant units of CS. Because this research had been supported by high level managers, the return rate of responses was $100 \% .33 \%$ of respondents were postgraduate, $52 \%$ graduate and $15 \%$ undergraduate or high school leaving degree with more than 10 years' work experience in the organization. The total experience average of respondents is 6 years. For assessing the reliability of the questionnaire, the consistency rate of each table was calculated (Saaty and Peniwati, 2007). For example, the consistency rate for pairwise comparison of criteria was 0.034 . Since this number is less than 0.1 , the consistency rate is acceptable (Saaty and Peniwati, 2007). So, the entries of pairwise comparison matrix were calculated. In this regard, the completed tables of questionnaires were analyzed. The results of these analyzes are the weights of criteria (Wi) and alternatives (Xij) (figure 5 and table 2).

The weights of contextual dimensions, illustrated in figure 5, can be interpreted in two levels: service organizations level; and the case study level. It shows that the size of organization is the most important criteria for structure designing in the service organizations. As we discussed before, the size reflects the number of people in the organization and consider to the

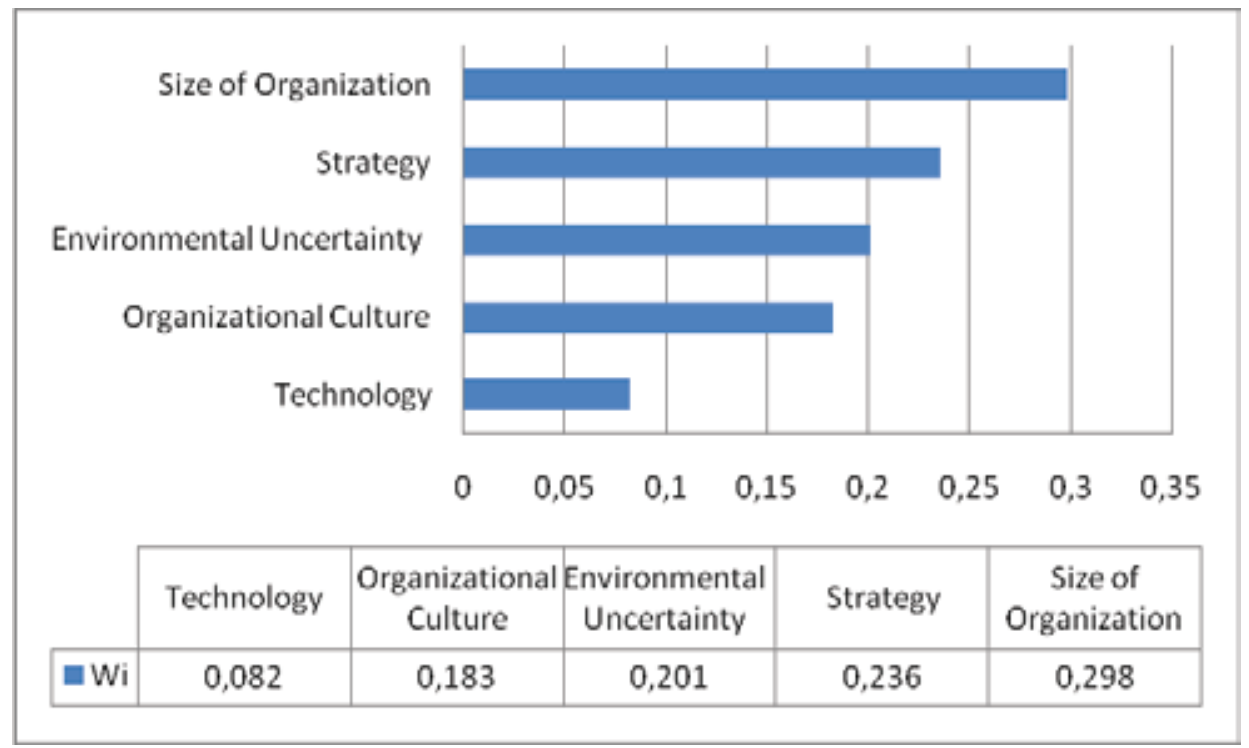

Figure 5: The weights of Criteria 
Table 2: The weight of each alternative related with each criteria

\begin{tabular}{rccccc}
\hline & Strategy & Environmental Uncertainty & Technology & Size of Organization & Organizational Culture \\
\hline S1 & 0.312 & 0.281 & 0.279 & 0.236 & 0.271 \\
S2 & 0.348 & 0.311 & 0.332 & 0.402 & 0.261 \\
S3 & 0.228 & 0.193 & 0.118 & 0.091 & 0.237 \\
S4 & 0.112 & 0.215 & 0.271 & 0.271 & 0.231 \\
\hline
\end{tabular}

Table 3: Final ranking

\begin{tabular}{ll}
\hline Rank & Recommended Alternative \\
\hline 1 & S2; Integration and structure design based on product \\
2 & S1; Correction of current structure based on task combination \\
3 & S4; Matrix of integration and structure design \\
4 & S3; Integration and structure design based on geographical region \\
\hline
\end{tabular}

organization as a social system. The next priority is strategy which indicates the purpose and competitive techniques of the organization. The low weight of technology in compare with other dimensions also means that this indicator has the least priority in this kind of organizations.

Discussion and results

Table 3 shows the final results of the organizational structures ranking. Therefore, from the expert's viewpoint, the product type of organizational structure is the most proposed structure for CS.

Therefore, the product organizational structure is a good selection for commercial parts of the companies with retail dealers in various cities. This selection also declines $9 \%$ of the commercial staff in the CS company.

\section{Conclusion}

Change in proper time is an axiomatic principle in all phenomena especially for organizations. Changing in organizational structure and determining an appropriate structure are the salient factors of successful organizations. Although the theories of structure design are rich, they have a detail-oriented thinking that make the determination of suitable structures with difficulty.

In this article, the researchers attempted to offer a model that could illustrate the effect of the contextual variables and dimensions on the selection of organizational structure in practice. A multi-attribute model of decision-making based on the fuzzy AHP was employed to prioritize and select a suitable organizational structure. The main accomplishments of the research are categorized in two groups. First, the priority of contextual dimensions in service organizations(figure 5) that shows the role of size and strategy in the structure designing of service organizations. Second, the selection of the most proper organizational structure based on a quantitative approach in which the direct effect of contextual dimensions is observable (table2). Other advantages of this approach are to participation of beneficiary staff in the process of decision-making, and to work as a supportive tool for managers to speed their changes programs.

As future studies, the application of this approach can be investigated in other kinds of organizations such as manufacturing, and other service organizations in different industries. Finally as a limitation of the mathematical approach, we should note that the EA method sometimes give the weight of zero in the process of calculations. Therefore, we also advise to prospective researchers to consider to other AHP Fuzzy methods such as Buckley's fuzzy AHP in their analysis and decion-making.

\section{References}

Adler, R.W. (2011). Performance management and organizational strategy: How to design systems that meet the needs of confrontation strategy firms, The British Accounting Review, 43(4), 251-263, http://dx.doi.org/10.1016/j.bar.2011.08.004

Al-Mashari, M. \& Zairi, M. (1999). BPR implementation process: an analysis of key success and failure factors, Business Process Management Journal, 5(1), 87-112. http://dx.doi. org/10.1108/14637159910249108

Aslani, A., Naaranoja, M. \& Zakeri, B. (2012a). The prime criteria for private sector participation in renewable energy investment in the Middle East (case study: Iran). Renewable and Sustainable Energy Reviews, 16(4), 1977-1987. http://dx.doi. org/10.1016/j.rser.2011.12.015 
Aslani, A., Helo, P. \& Naaranoja, M. (2012b). Development of creativity in concurrent engineering teams, American Journal of Industrial and Business Management, 2(3), 77-84, http://dx.doi. org/10.4236/ajibm.2012.23010

Azar, A. (2008). Fuzzy Management Science [in Persian]. Tehran: IMPSC.

Bafandeh, A. (2009). Developing a fuzzy expert system in order to design the organizational structure [in Persian], Beyond the Management, 9(2), 103-128.

Bennett, R. \& Savani, S. (2004). Managing conflict between marketing and other functions within charitable organizations, Leadership \& Organization Development Journal, 25(2), 180 - 200, http://dx.doi.org/10.1108/1437730410521840

Cernancky, M., Makula, M. \& Benuskova, L. (2007). Organization of the state space of a simple recurrent network before and after training on recursive linguistic structures, Neural Networks, 20(2), 236-244, http://dx.doi.org/10.1016/j.neunet.2006.01.020

Chang, D.Y. (1996). Theory and methodology: applications of the extent analysis method on fuzzy AHP, European Journal of Operational Research, 95(3), 649-655, http://dx.doi. org/10.1016/0377-2217(95)00300-2

Chou, T.C. \& Cheng, S.C. (2006). Design and implementation of a semantic image classification and retrieval of organizational memory information systems using analytical hierarchy process, Omega, 34(2), 125-134, http://dx.doi.org/10.1016/j. omega.2004.08.004

Daft, R.L. (2009). Organization Theory and Design (Tenth Edition). US: South-Western Cengage Learning.

Damjanovic, V. (2010). Semantic reengineering of business processes, Information Systems, 35(4), 496-504, http://dx.doi. org/10.1016/j.is.2009.06.003

Dessler, G. (2007). Human Resource Management (11 ${ }^{\text {th }}$ Edition). US: Prentice Hall.

DuBrin, A.J. (2006). Fundamentals of Organizational Behavior $\left(4^{\text {th }}\right.$ editions). US: South-Western College Pub.

Grover, V., Jeong, S.R., Kettinger, W.J \& Teng, T.C. (1995). The implementation of business process re-engineering, Journal of Management Information Systems, 12(1), 109 - 144.

Hall, J.M. \& Johnson, M.E. (2009). When Should Process Be Art, Not Science, Harvard Business Review, Retrieved July 20, 2012, from http://www.virginia.edu/sciartproject/docs/ WhenShouldaProcessBeArt.pdf

Hatch, M.J. \& Cunliffe, Al. (2006). Organization Theory: Modern, Symbolic, and Postmodern Perspectives( $2^{\text {nd }}$ edition). Oxford: Oxford University Press.

Hwang, C.L. \& Yoon, K (1981). Multiple Attribute Decision-Making; Methods and Applications- a State of the Art Survey, Berlin: Springer-Verlag.
Ishizaka, A. \& Labib, A. (2011). Review of the main developments in the analytic hierarchy process, Expert Systems with Applications, 38(11), 14336-14345, http://dx.doi.org/10.1016/j. eswa.2011.04.143

Ketchen, D.J. \& Hult, T.M. (2007). Toward greater integration of insights from organization theory and supply chain management, Journal of Operations Management, 25(2), 455-458, http://dx.doi.org/10.1016/j.jom.2006.05.001

Mintzberg, H. (2007). Mintzberg on Management. New York: The Free Press.

Momeni, M. (2007). New Topics in the Operations Research [in Persian]. Tehran: University of Tehran.

Patton, M.Q. (2002). Qualitative Research and Evaluation Methods. London: SAGE.

Robbins, S.P. (2006). Organization Theory: Structure, Design and Application. USA: Pearson Academic.

Sarmad, Z. (2009). The Research Method in Behavioral Science [in Persian]. Tehran: Aghah.

Saaty, T.L. \& Peniwati K. (2007). Group Decision Making: Drawing out and Reconciling Differences. Pennsylvania: RWS Publications.

Sethi, R. \& Nicholson, C.Y. (2001). Structural and contextual correlates of charged behavior in product development teams, Journal of Product Innovation Management, 18(3), 154-168. http:// dx.doi.org/10.1111/1540-5885.1830154

Alireza Aslani, project researcher and lecturer, is a doctoral student in the Department of Production (Industrial Management) at the University of Vaasa, Finland. Currently, he is a visiting scholar of the Department of Engineering and Public Policy in Carnegie Mellon University, USA. He got his MSc in MBA (strategic thinking and management) and BSc in Mechanical engineering (Energy). His research interests include quantitative decision-making, renewable energies (business and technology aspects), complex project management, and system dynamics and thinking.

Feryal Aslani is a MSc student in the Department of Information Technology at the University of Tehran, Iran. She got her BSc in administration management and studies. Her research interests are knowledge management and sharing, organization behavior, and business process re-engineering. 